Received: 2013.11.24 Accepted: 2013.12.18 Published: 2014.03.18

Authors' Contribution: Study Design A Data Collection B Statistical Analysis C Data Interpretation D Manuscript Preparation E

Literature Search F Funds Collection G

\section{Congenital arhinia: A rare case}

\author{
B 1 Mao-mao Zhang \\ E 2 Yang-hong Hu \\ F 1 Wei He \\ G 1 Kui-kui Hu
}

1 Department of Plastic Surgery, Guangdong Women and Children's Hospital, Guangzhou Medical University, Guangzhou, China

2 Department of Plastic Surgery, Second Affiliated Hospital To Nanchang University, Nanchang, China

\begin{abstract}
Patient: Male, 4 months
Final Diagnosis: Congenital arhynia

Symptoms: Absence of the nose

Medication: -

Clinical Procedure: -

Specialty: Pediatrics and Noenatology • Genetics

Objective: Congenital defects

Background: Congenital nasal absence (arhinia) is an extremely rare malformation. Arhinia causes severe airway obstruction and poor feeding in the affected neonate. There is an association with other facial anomalies, especially defects of the eyes, ears, palate, and midline defects.

Case Report: A full-term boy was born via an uncomplicated vaginal delivery. The mother was 40 years old and had a normal pregnancy. The mother had 4 previous uncomplicated pregnancies. There was no history of drug use during pregnancy.

Conclusions: Congenital arhinia is a rare defect of embryogenesis, often associated with other anomalies that significantly influence the immediate and long-term outcomes of the neonate. It is a potentially life-threatening condition and requires the presence of a highly skilled neonatal resuscitation team at the time of delivery. Parental counseling is vital and a multidisciplinary team approach is required to optimize neonatal outcome.
\end{abstract}

Keywords: Arhinia $\bullet$ Congenital $・$ Reconstruction

Full-text PDF: http://www.amjcaserep.com/download/index/idArt/890072 


\section{Background}

Congenital nasal absence, with only 43 cases reported in the literature since the first report in 1931, is an extremely rare malformation [1-19]. The lack of an external nose is generally one part of a complex malformative syndrome characterized by the absence of nasal cavities, microphthalmia or coloboma of olfactory bulbs (12 cases), high arched palate (20 cases), coloboma of iris (8 cases), and microtia.

\section{Case Report}

A healthy 40-year-old G5P5 (Gravida 5 and Para 5) woman delivered a live male infant weighing $2.89 \mathrm{~kg}$ by spontaneous vaginal delivery at term. There was neither a family background of congenital malformations nor a history of any medications during the pregnancy. The prenatal course was uncomplicated. At birth, we found that the baby showed absence of the nose, nasal root, and nasal pits. There were longitudinal ridge-like protuberances in the mid-face, which were $0.2 \mathrm{~cm}$ tall (Figure 1). Shortly after birth, the infant was transferred to the neonatal intensive care unit for further evaluation and monitoring. The baby was relieved by an oropharyngeal tube due to severe shortness of breath.

We found that the baby was born deformed: microphthalmia, auris dextra microtia, right side anorchia, small penis, high arched palate, and hypoplasia of bilateral maxillary sinus and ethmoid sinus (Figures $2 \mathrm{~A}$ and $2 \mathrm{~B}$ ), but the intracranial structure was normal (Figure 3 ). The chromosomes of normal male children are $46+X Y$. Physical examination showed dyspnea and tachypnea with mouth-breathing movements at birth. However, the situation had greatly improved 1 month later: the baby could adapt to oral breathing independently and could suck and breathe simultaneously. The infant's liver enzymes, renal function, and serum electrolytes were all

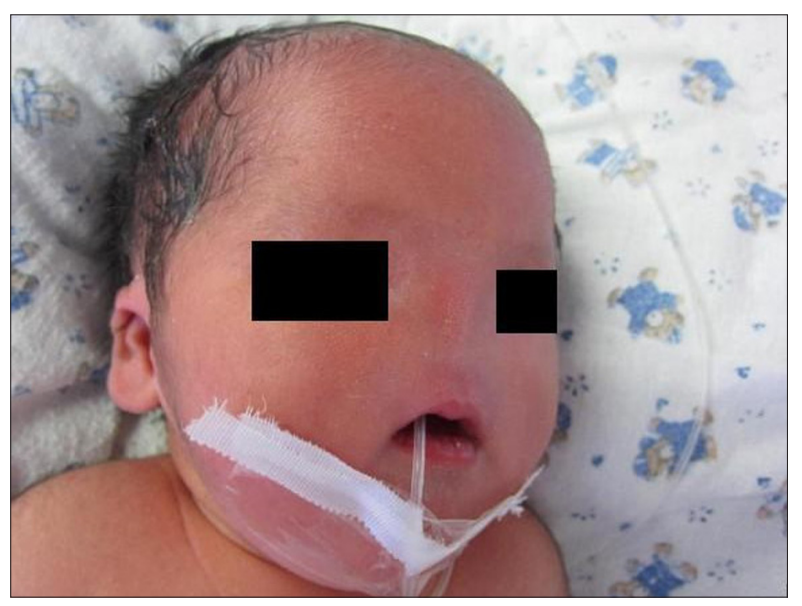

Figure 1. Clinical photograph.

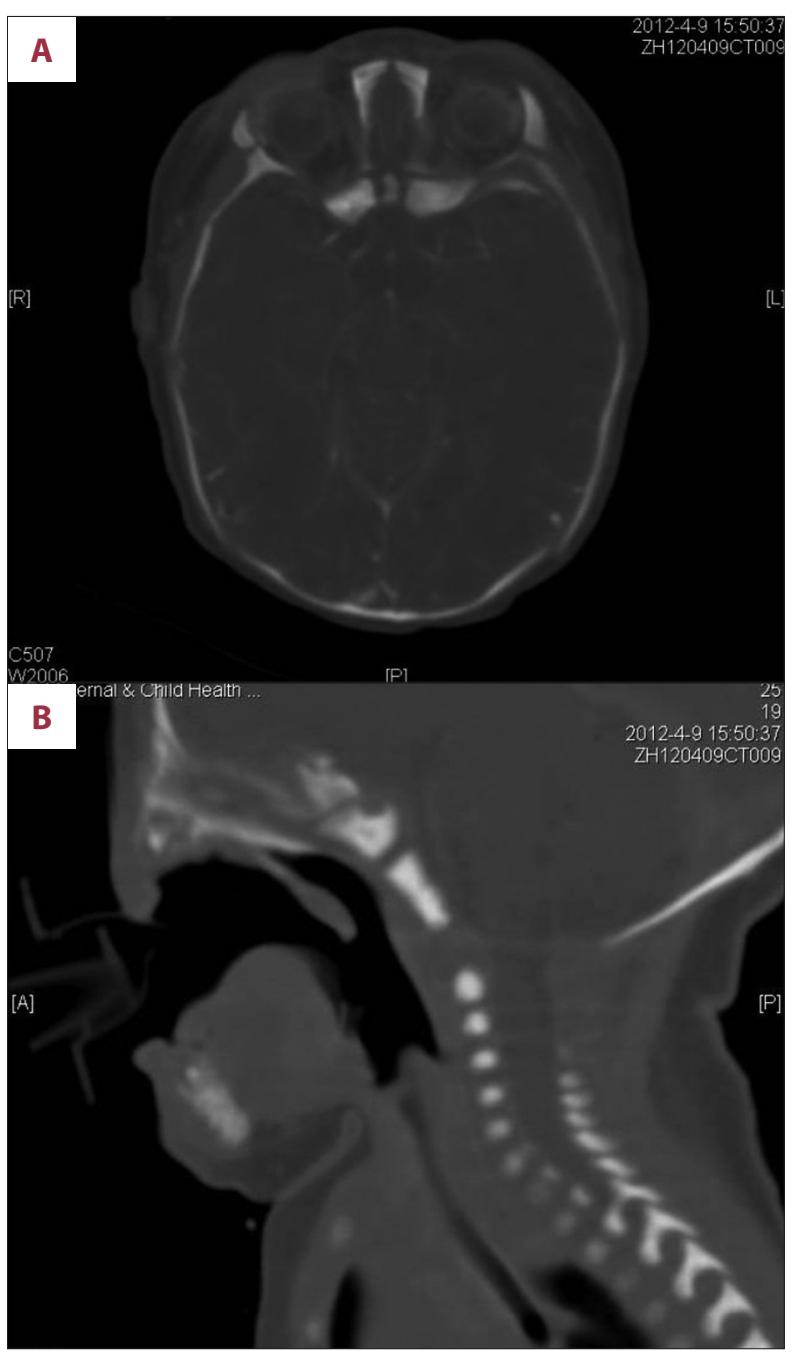

Figure 2. (A, B) CT scan showing narrow nasal cavity with pyriform aperture and choanal atresia.

within normal range. Ultrasonograms of the heart, abdomen, and brain were all normal.

\section{Discussion}

Facial growth is closely related to branchial arches differentiation and nasal development including the differentiation of surface protrusion and surface protrusion joint fusion. The embryological development of the nose occurs between the third and eighth week of life [20]. At 24 days of life, the face consists of a superior frontal process, paired bilateral maxillary processes in the mid-face, and paired bilateral mandibular processes caudally [21]. The maxillary and mandible process are separated by the primitive mouth (oral pit or stomadeum) [22]. Two fast-growing ridges ('nasal placodes') develop in the fifth week, forming the medial and lateral nasal swellings and giving rise to the nasal pits between the swellings. The medial 


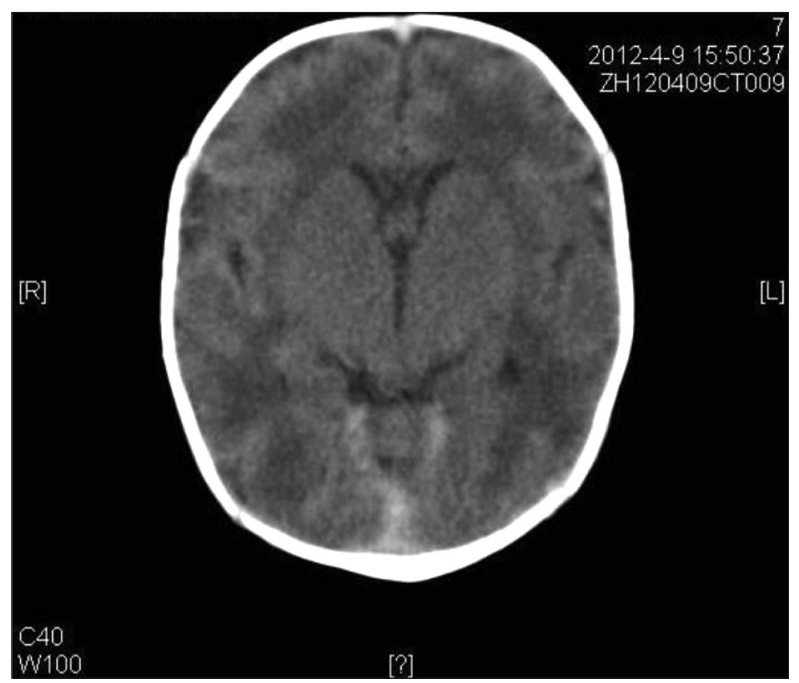

Figure 3. The structure of intracranial is normal.

swellings fuse to form the nasal septum. In the $6^{\text {th }}$ week, maxillary and frontal process fuses to form the rudimentary palatal shelves. Cells within the nasal pits continue to migrate posteriorly to form the primitive nasal cavities, which are separated from the buccal cavity by the rudimentary palatal shelves [9]. At 7 to 8 weeks, the baby's face looks like an adult face after every face process has merged. The shape of the nose varies in width and flatness, the nostrils towards the front and separated from each other farther, and the eyes are located on the outside of the head and hypertelorism.

Because arhinia is exceptionally rare, the pathogenesis of this disease has not been fully understood. It is postulated that lack of development of the nose results from medial failure and lateral nasal process growth, but it is also possible that overgrowth and premature fusion of the nasal medial process result in the formation of the atretic plate [17]. Several genes involved in nose and facial development have been shown to be causes of arhinia. However, no consistent gene mutations have been discovered; therefore, genetic testing is not yet available. The chromosomal analysis in patients with arhinia showed normal results, excepting 3 cases that had abnormal karyotypes: $\operatorname{mos} 46, \mathrm{XX} / 47, \mathrm{XX},+9 ; 1046, \mathrm{XY}, \mathrm{inv}(9) ; 1146, \mathrm{XX}, \mathrm{t}(3 ; 12)$ (q13.2;p11.2) [10]. In addition to the karyotype, the all reported cases are normal.

Factors of deformity gene and the mother are still unknown. Ruprecht et al. [5] reported that 2 sisters were born into a healthy family and suffered from arhinia at the same time. This is the first report in the literature of familial arhinia. Moreover, Claudia et al. [18] reported on a sister and brother who suffered from arhinia at the same time. Three mothers had medication during pregnancy: 2 of them [12,15] did not know about their medication and the other one [14] took a medicine called "escitalopram oxalate". However, this baby was not born because pregnancy was terminated at the $29^{\text {th }}$ week [13]. Most of the pregnant women did not have any other abnormal status in pregnancy. Down syndrome [7], hypertension, and diabetes [8] are the relatively common complications of mothers during pregnancy. Some cases are born without any difficulty in breathing or other symptoms. Most cases have a normal life, and some have married and have children without any surgical treatment [16]. Three infants died in the first 2 month of life: 1 had respiratory insufficiency at $2 \mathrm{~h}$ of age, 1 had sepsis secondary to surgical creation of a nasal airway at 29 days of age, and 1 died of sepsis at 10 weeks of age. The clinical consequences of congenital arhinia are severe airway obstruction and inability to feed. The nursing care for children is especially important because the infant cannot eat and breathe at the same time without the normal nose function, which results in respiratory distress. A surgically created nasal airway or a tracheostomy tube is an important part of early management. The surgical correction of the nasal airway during the neonatal period has been advocated to reduce the potential of dependency on mouth breathing or tracheostomy. Feeding difficulties secondary to impaired simultaneous sucking and breathing may be overcome by placement of an orogastric tube or a gastrostomy tube [11].

The reconstruction of arhinia is very complex and it should be performed only by a multidisciplinary team that includes otolaryngology, plastic surgeons, and prosthodontists. The arhinia reconstruction progress mainly consists of 2 parts: reconstruction of the nasal cavity and reconstruction of the external nose. There are 2 methods of nasal cavity reconstruction. Two separated nasal cavities are created with a dental drill, then silicone tubes keep the new nasal cavities patent $[2,4]$. Another method is called Le Fort II maxillary osteotomy. This was extended through the maxillozygomatic consoles and toward the medial end of the inferior orbital rim and ran through the infraorbital foramen. A horizontal arm linked the 2 sides. Then the maxilla was down-fractured, and a wide median nasal cavity was created with a round bur, reaching posteriorly to the upper portion of the rhinopharynx $[17,19]$. If the height of maxillary is high enough, the patient only needs Le-Fort II osteotomy; If not, the patient should have a Le-Fort II osteotomy first, and then extend it along the maxillary bone. The external distraction device provides additional facial height in a reasonable time period and has sufficient midfacial vertical length to accommodate a nasal reconstruction [10]. There are 2 advantages of lengthening of maxilla: it can provide enough maxillary height for the reconstruction of nasal cavity, and it achieves suitable aesthetic proportions [11]. Surgical methods of treatment for arhinia include staged reconstruction or simultaneous reconstruction of the nasal passage and the external nose. We found that there are more reports of staged reconstruction than of simultaneous reconstruction $[2,3,6,19]$. There are 3 suggestions about nasal reconstruction timing: 
1. Early reconstruction (neonatal);

2. Preschool or school-age;

3. Adolescence (after nasal and maxillofacial development perfectly).

Surgical reconstruction of the external nose and inner cavities should consider factors such as the characteristics of nasal growth and psychological impact on the child. Most authors agree that reconstruction can be delayed at least until preschool years when facial development is nearly completed [4]. The nose grows on average $20.9 \mathrm{~mm}$ in length from age 1 to 18 years, $43.1 \%$ of the growth increment is achieved between age 1 and 5 years, and a large proportion of the remaining growth occurs between age 5 and 8 years. The nasal tip protrusion approximately follows

\section{References:}

1. Blair VP, Brown JB: Nasal abnormalities, fancied and real. Surg Gynecol Obstet, 1931; (53): 796-819

2. Gifford GJ, Swanson L, MacCollum DW: Congenital absence of the nose and anterior nasopharynx. Report of two cases. Plast Reconstr Surg, 1972; 50(1): 5-12

3. Lutolf U: Bilateral aplasia of the nose: a case report. J Maxillofac Surg, 1976; 4(4): 245-49

4. Muhlbauer W, Schmidt A, Fairley J: Simultaneous construction of an internal and external nose in an infant with arhinia. Plast Reconstr Surg, 1993; 91(4): 720-25

5. Galetti R, Dallari S, Bruzzi M et al: [Considerations concerning respiratory physiopathology in a case of total arhinia]. Acta Otorhinolaryngol Ital, 1994; 14(1): 63-69 [in Italian]

6. LaTrenta GS, Choi HW, Ward RF et al: Complete nasal agenesis with bilateral microphthalmia and unilateral duplication of the thumb. Plast Reconstr Surg, 1995; 95(6): 1101-4

7. Cusick W, Sullivan CA, Rojas B et al: Prenatal diagnosis of total arhinia. Ultrasound Obstet Gynecol, 2000; 15(3): 259-61

8. Olsen $\emptyset \mathrm{E}$, Gjelland K, Reigstad H, Rosendahl K: Congenital absence of the nose: a case report and literature review. Pediatr Radiol, 2001; 31(4): 225-32

9. McGlone L: Congenital arhinia. J Paediatr Child Health, 2003; 39(6): 474-76

10. Feledy JA, Goodman CM, Taylor T et al: Vertical facial distraction in the treatment of arhinia. Plast Reconstr Surg, 2004; 113(7): 2061-66

11. Hou JW: Congenital arhinia with de novo reciprocal translocation, $t(3 ; 12)$ (q13.2;p11.2). Am J Med Genet A, 2004; 130A(2): 200-3 the same growth pattern. At 1 year, the nose width is already growing to adult size, measuring $79.5 \%$ of the mature width.

\section{Conclusions}

Internal and external nasal reconstruction is the most important treatment of arhinia and can reduce negative effects on patient psychology and physiology. Maxillary osteotomy with a down-fracture is an important step of nasal cavity reconstruction. Forehead expansion, forehead flap elevation, construction of a nasal framework with costochondral grafts, and long-term nostril splinting are essential for obtaining durable morphologic and functional success.

12. Cho $\mathrm{CH}$, Shakibaei $\mathrm{M}$, Merker $\mathrm{HJ}$, Klein $\mathrm{M}$ : [The rare malformation of nasa aplasia]. Mund Kiefer Gesichtschir, 2006; 10(2): 106-17

13. Graham JJ, Lee J: Bosma arhinia microphthalmia syndrome. Am J Med Genet A, 2006; 140(2): 189-93

14. Akkuzu G, Akkuzu B, Aydin E et al: Congenital partial arhinia: a case report. J Med Case Rep, 2007; 1: 97

15. Goyal A, Agrawal V, Raina VK, Sharma D: Congenital arhinia: A rare case. J Indian Assoc Pediatr Surg, 2008; 13(4): 153-54

16. Meng LJ, Huang ZL, Niu L: [Congenital arhinia: one case report]. Zhonghua Er Bi Yan Hou Tou Jing Wai Ke Za Zhi, 2009; 44(4): 343-44

17. Thornburg LL, Christensen N, Laroia N, Pressman EK: Prenatal diagnosis of total arhinia associated with normal chromosomal analysis: a case report. J Reprod Med, 2009; 54(9): 579-82

18. Fakhraee SH, Nariman S Taghipour R: Congenital arhinia: case report of a rare congenital anomaly. Arch Iran Med, 2011; 14(5): 355-56

19. Brusati R, Colletti G: The role of maxillary osteotomy in the treatment of arhinia. J Oral Maxillofac Surg, 2012; 70(5): e361-68

20. Nishimura Y: Embryological study of nasal cavity development in human embryos with reference to congenital nostril atresia. Acta Anat (Basel), 1993; 147(3): 140-44

21. Lee KJ: Embryology of clefts and pouches. In: Essential Otolaryngology Head and Neck Surgery. Lee KJ, Lee KJ (eds.), Medical Examination Publishing New York. 1991; 304-6

22. Castillo $M$ : Congenital abnormalities of the nose: $C T$ and MR findings. Am J Roentgenol, 1994; 162(5): 1211-17 